\title{
Aminofluoresceins vs Fluorescein: Peculiarity of Fluorescence
}

Nikolay O. Mchedlov-Petrossyan, ${ }^{* 1}$ Tatyana A. Cheipesh, ${ }^{1}$ Alexander D. Roshal, ${ }^{1}$ Sergey V. Shekhovtsov, ${ }^{1}$ Elena G. Moskaeva, ${ }^{1}$ Iryna V. Omelchenko ${ }^{2}$

\section{Contents}

1. The results of X-ray study of 4'-nitrofluorescein.

2. Dependences of absorption and fluorescence maxima and quantum yields on the Reichardt's parameter of solvent polarity.

3. The results of DFT calculations for fluorescein dyes.

${ }^{*}$ Correspondence to: N. O. Mchedlov-Petrossyan, V.N. Karazin Kharkov National University, 61022 Kharkov, Ukraine, e-mail: nikolay.mchedlov@ gmail.com 


\section{The results of X-ray study of 4'-nitrofluorescein.}

4'-Nitrofluorescein was obtained for X-ray study in form of a cation, with $\mathrm{Cl}^{-}$as counterion. The structure of the cation is given in Scheme S1.

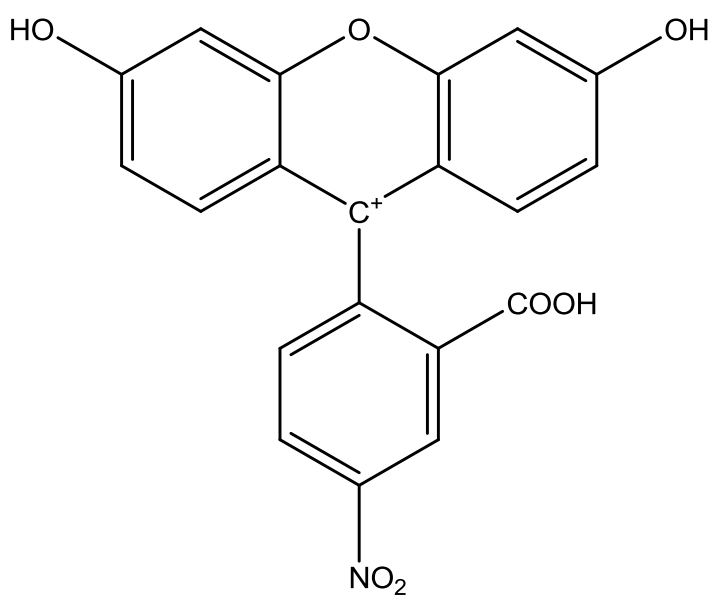

Scheme S1. Structure of 4'-nitrofluorescein cation

Asymmetric part of the unit cell of the crystal contains 4'-nitrofluorescein carbocation, chloride anion, and two water molecules (Fig. S1). Planar configuration of the $\mathrm{C}(1)$ atom (sum of bond angles centered on $\mathrm{C}(1)$ is $359.9(7)^{\circ}$ ) and of the xanthene moiety in whole (within $0.013 \AA$ ) clearly indicate localization of the positive charge on $\mathrm{C}(1)$ atom (Scheme S1). It is stabilized over the $\pi$ system of xanthene $(\mathrm{C}(1)-\mathrm{C}(2)$ and $\mathrm{C}(1)-\mathrm{C}(8)$ bonds adopt lengths of 1.399(4) $\AA$ and 1.397(4) $\AA$ that is close to mean value in aromatic rings $1.397 \AA ;^{1}$ the $C(14) \ldots C(19)$ benzene ring does not participate in conjugation with $\mathrm{C}(1)$ (benzene ring plane is rotated around the xanthene plane on $96^{\circ}$, the $\mathrm{C}(1)-\mathrm{C}(14)$ distance is $1.494(4) \AA$ that is typical for cyclic forms of fluorescein derivatives (mean value $1.513 \AA{ }^{2}$ ).

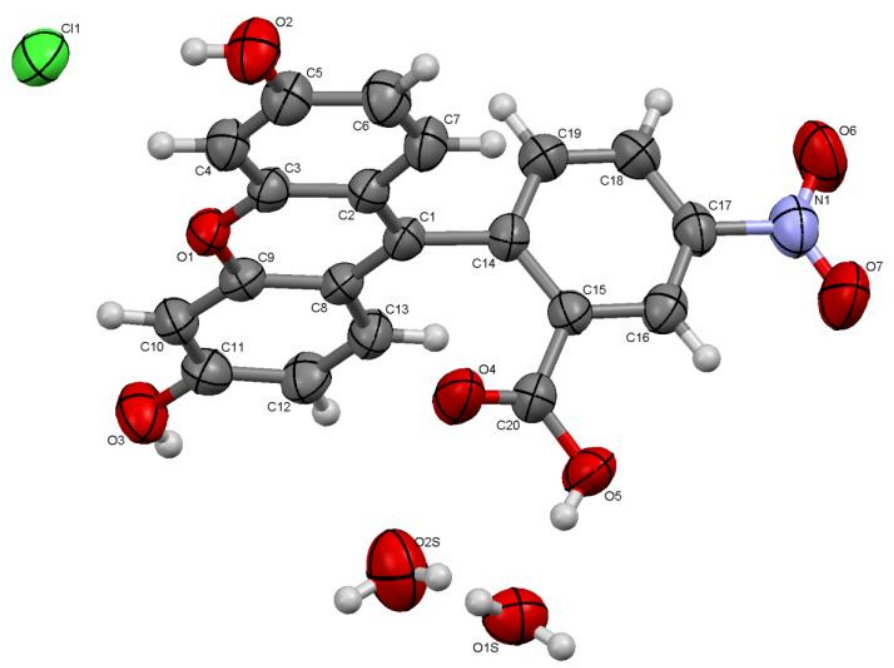

Figure S1. Structure of 4'-nitrofluorescein cation according to the X-ray diffraction data, including solvate molecules. 
Nitro group is coplanar to benzene ring plane (angle is $2.3^{\circ}$ ) that is favorable for attractive intramolecular $\mathrm{O} \ldots \mathrm{H}$ contacts $\mathrm{O}(6) \ldots \mathrm{H}(18)$ and $\mathrm{O}(7) \ldots \mathrm{H}(16)$ of $2.41 \AA$ (sum of van der Waals radii is $2.46 \AA,^{3}$ ). Carboxyl groups is slightly rotated (angle is $14.8^{\circ}$ ) due to repulsion with $\mathrm{C}(1$ ) atom (short contact $\mathrm{C}(1) \ldots \mathrm{O}(4) 2.67 \AA$, sum of vdW radii is $3.00 \AA$ ). The essential difference in $\mathrm{C}$ O bond lengths in carboxyl group $(\mathrm{C}(20)-\mathrm{O}(4)$ is $1.207(3) \AA$ and $\mathrm{C}(20)-\mathrm{O}(5)$ is $1.297(3) \AA)$ indicate that the group is protonated at the $\mathrm{O}(5)$ atom.

All ions and molecules in the crystal participate an extended system of intermolecular $\mathrm{O}-\mathrm{H}$...O

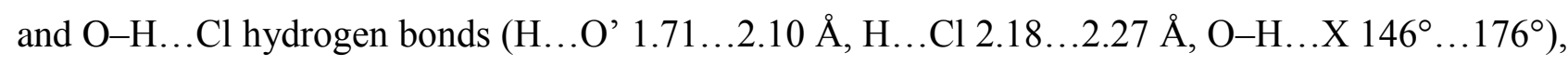
that form layers parallel to $(-1,1,0)$ crystallographic plane. Layers are linked by stacking between nitrobenzoic moieties involving $\pi$-systems of benzene ring and nitro group (fragments are coplanar, interplanar separation $3.40 \AA$, plane shift $1.86 \AA$ ), as well as couple of weak C-H... (H...O $2.50 \ldots 2.51 \AA)$ and $\mathrm{C}-\mathrm{H} \ldots \pi(\mathrm{H} \ldots \mathrm{C} 2.76 \ldots 2.87 \AA)$ contacts.

\section{References}

(1) H.-B. Bürgi and J. D. Dunitz, Structure Correlation, vol. 2, VCH, Weinheim, Germany, 1994.

(2) Groom, C. R.; Allen, F. H. The Cambridge structural database in retrospect and prospect. Angew. Chem. Int. Ed. 2014, 53, 662-671.

(3) Zefirov, Y. V; Zorkii, P. M. Van der Waals radii and their application in chemistry. Russ. Chem. Rev. 1989, 58 (5), 421-440. 
2. Dependences of absorption and fluorescence maxima and quantum yields on the Reichardt's parameter of solvent polarity
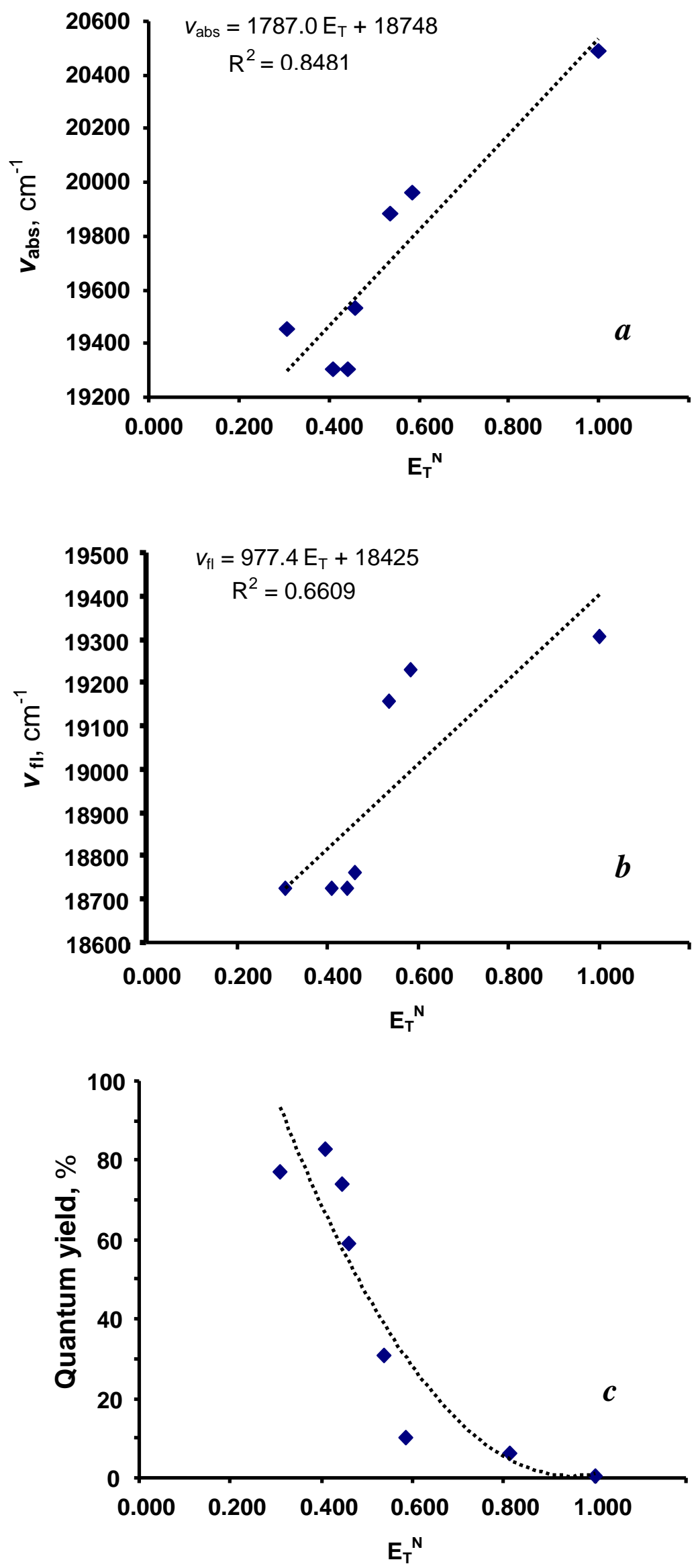

Figure S2. Plots of absorption band maxima $(a)$, fluorescence band maxima $(b)$ and quantum yields $(c)$ against values of Reichardt's solvent polarity parameter $\left(\mathrm{E}_{\mathrm{T}}\right)$ for 4'-aminofluorescein dianion. 

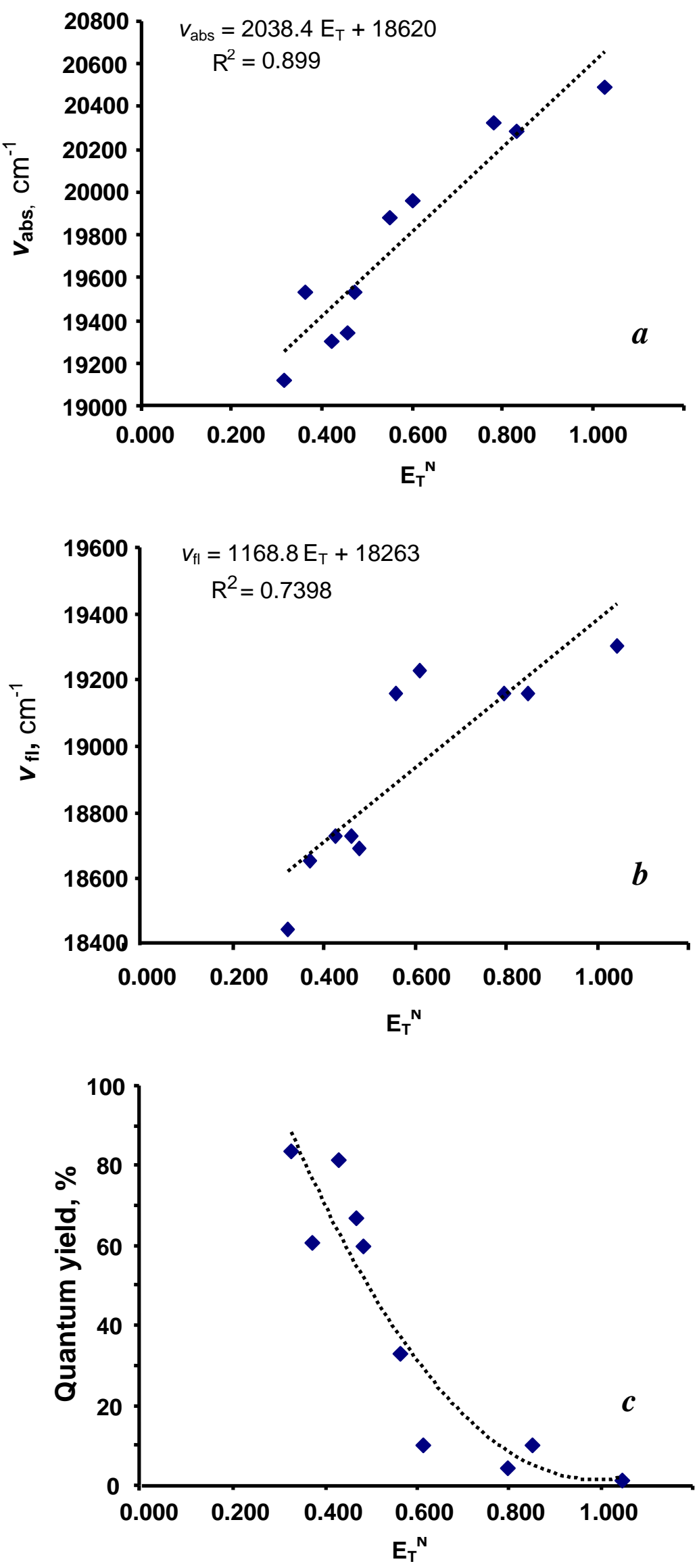

Figure S3. Plots of absorption band maxima $(a)$, fluorescence band maxima $(b)$ and quantum yields $(c)$ against values of Reichardt's solvent polarity parameter $\left(\mathrm{E}_{\mathrm{T}}\right)$ for 5 '-aminofluorescein dianion. 

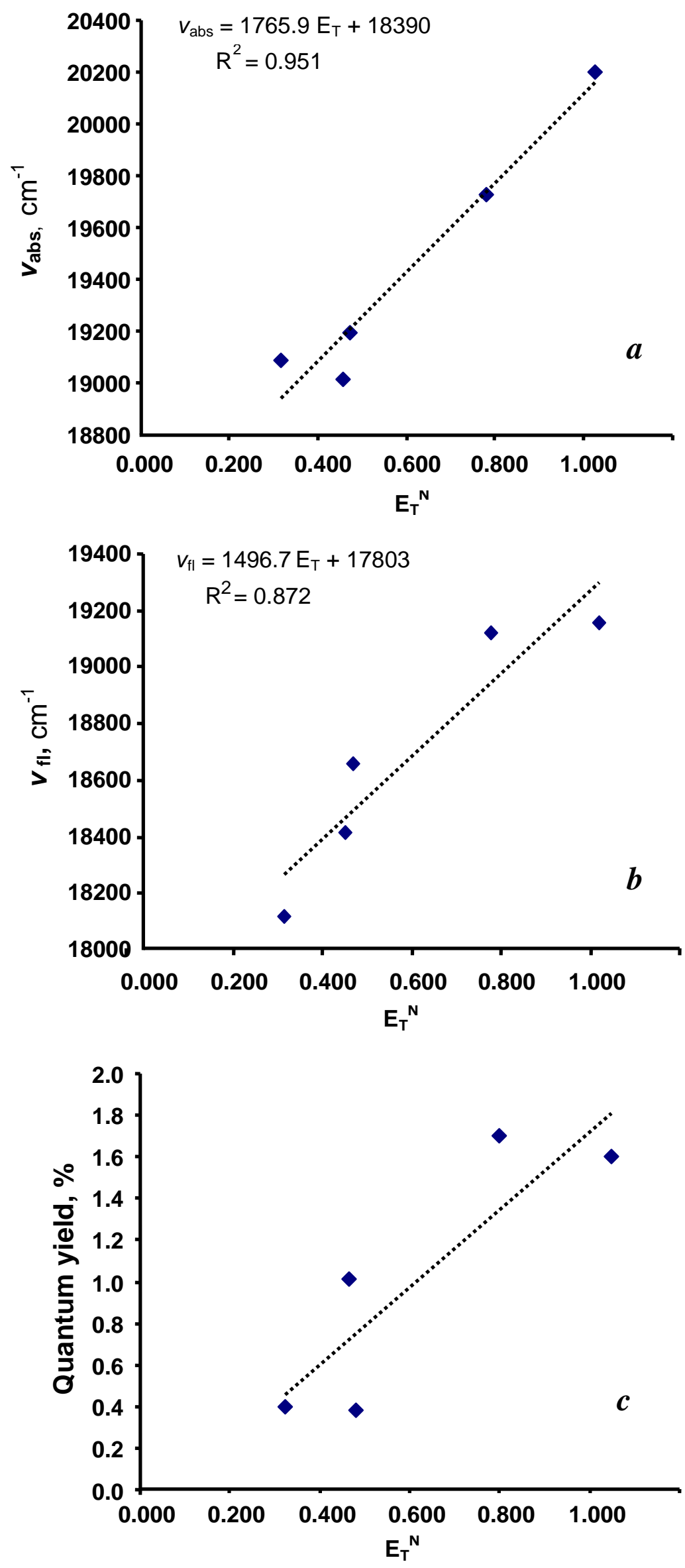

Figure S4. Plots of absorption band maxima (a), fluorescence band maxima $(b)$ and quantum yields $(c)$ against values of Reichardt's solvent polarity parameter $\left(\mathrm{E}_{\mathrm{T}}\right)$ for 4'-nitrofluorescein dianion. 


\section{Results of DFT calculations for fluorescein dyes}

Table S1. Electrical charges on xanthene and phenyl fragments of fluoresceins in the ground and excited states $^{\text {a }}$

\begin{tabular}{|c|c|c|c|c|c|c|}
\hline \multirow{2}{*}{ Compound } & \multicolumn{2}{|c|}{$\begin{array}{c}\text { Charge on xantene } \\
\text { fragment in } \mathrm{S}_{0} \text {-state }\end{array}$} & \multicolumn{2}{c|}{$\begin{array}{c}\text { Charge on xantene } \\
\text { fragment in } \mathrm{S}_{1} \text {-state }\end{array}$} & \multicolumn{2}{c|}{$\begin{array}{c}\text { Interfragmental charge } \\
\text { transfer }^{\mathrm{b}}\end{array}$} \\
\hline & isolated & H-bonded & isolated & H-bonded & isolated & H-bonded \\
\hline Fluorescein & -1.073 & -1.209 & -0.986 & -1.160 & 0.087 & 0.049 \\
\hline 5'-Aminofluorescein & -0.999 & -1.173 & -0.873 & -1.127 & 0.126 & 0.045 \\
\hline 4'- Aminofluorescein & -0.999 & -1.179 & -0.838 & -1.136 & 0.160 & 0.040 \\
\hline 4'-Nitrofluorescein & -0.932 & -1.394 & -0.206 & -1.082 & -0.726 & 0.303 \\
\hline
\end{tabular}

${ }^{a}$ All the charges in the table are presented in units of $\overline{\mathrm{e}}$.

${ }^{\mathrm{b}}$ Charge transfer from side phenyl fragment onto xantene fragment has positive sign.

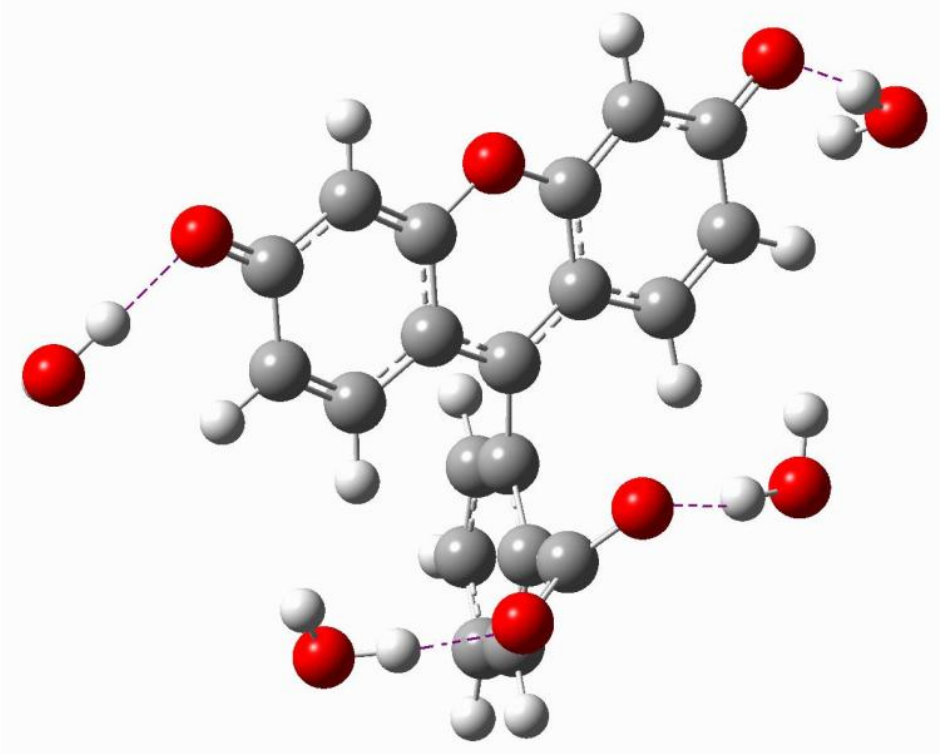

Figure S5. Structure of hydrogen-bonded unsubstituted fluorescein 
Table S2. Theoretical parameters of electronic transition $\Psi\left(S_{0} \rightarrow S_{1}\right)$.

\begin{tabular}{|c|c|c|c|c|c|c|}
\hline Compound & State & $\begin{array}{l}\text { Config. } \\
\text { interaction }\end{array}$ & $\begin{array}{l}\text { Transition } \\
\text { localization }\end{array}$ & $\begin{array}{l}\text { Energ } \\
\mathrm{y}, \mathrm{eV}\end{array}$ & $\lambda, \mathrm{nm}$ & $\begin{array}{c}\text { Oscillator } \\
\text { strengh }\end{array}$ \\
\hline \multirow{2}{*}{ Fluorescein } & Isolated & $0.69 \chi_{1 \rightarrow 1}$ & \multirow{2}{*}{ xanthene } & 3.11 & 398 & 0.705 \\
\hline & H-bonded & $0.63 \chi_{1 \rightarrow 1}$ & & 3.06 & 406 & 0.704 \\
\hline \multirow[b]{2}{*}{ 5'-Aminofluorescein } & Isolated & $0.70 \chi_{1 \rightarrow 1}$ & \multirow[b]{2}{*}{ xanthene } & 3.11 & 398 & 0.701 \\
\hline & H-bonded & $0.70 \chi_{1 \rightarrow 1}$ & & 3.05 & 407 & 0.703 \\
\hline \multirow{2}{*}{ 4'- Aminofluorescein } & Isolated & $0.70 \chi_{1 \rightarrow 1}$ & \multirow{2}{*}{ xanthene } & 3.11 & 398 & 0.703 \\
\hline & H-bonded & $0.70 \chi_{1 \rightarrow 1}$ & & 3.06 & 406 & 0.704 \\
\hline \multirow[b]{2}{*}{ 4'-Nitrofluorescein } & Isolated & $0.70 \chi_{1 \rightarrow 1}$ & \multirow[b]{2}{*}{$\begin{array}{l}\text { ICT xantene } \\
\rightarrow \text { phenyl }\end{array}$} & 2.48 & 499 & 0.006 \\
\hline & H-bonded & $\begin{array}{c}0.67 \chi_{1 \rightarrow 1} \\
+ \\
0.22 \chi_{1 \rightarrow 2}\end{array}$ & & 2.81 & 442 & 0.344 \\
\hline
\end{tabular}
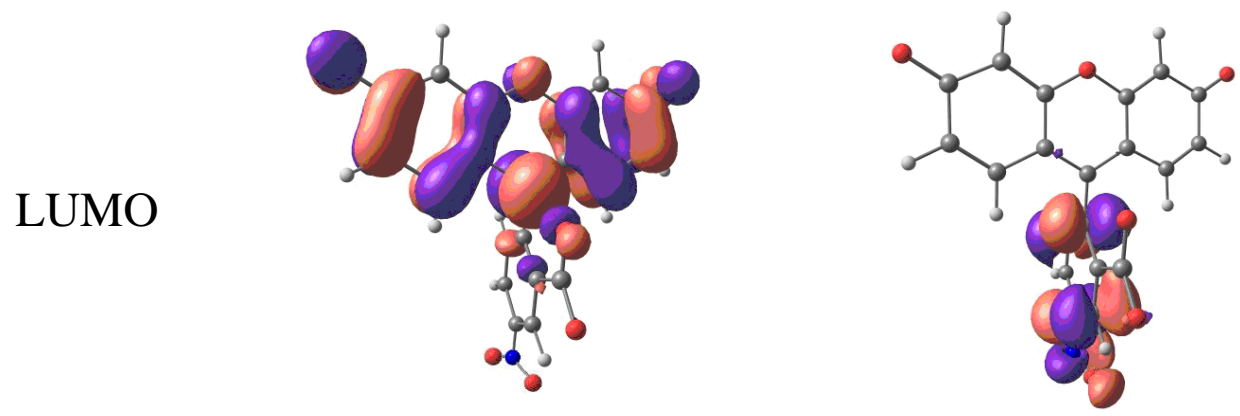

HOMO
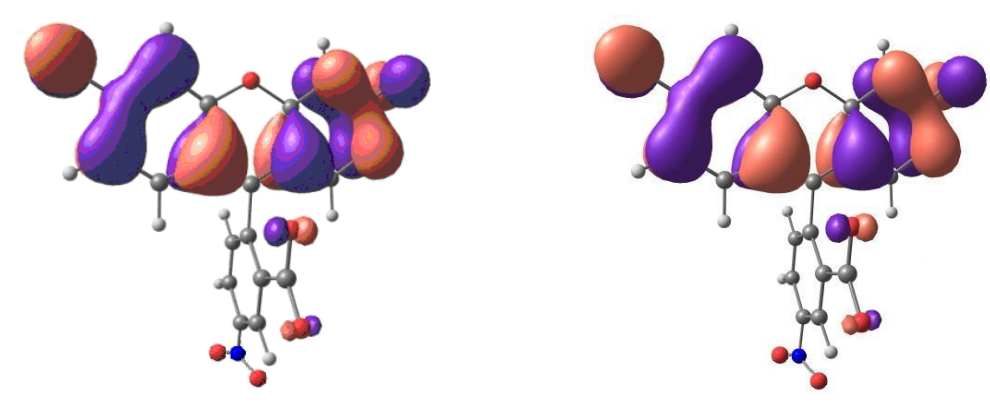

$a$

$b$

Figure S6. Highest occupied and lowest unoccupied molecular orbitals of dianions of non-substituted $(a)$ and 4'-nitro $(b)$ fluoresceins 